\title{
Congenital Descending Colonic Stenosis with Perforation of Transverse Colon in a Neonate:A Case Report
}

\author{
Hamid $\mathbf{R}^{1}$, Shera $\mathrm{AH}^{2}$, Bhat NA ${ }^{3}$, Baba $\mathrm{A}^{4}$, Rashid $\mathrm{A}^{5}$ \\ ${ }^{1}$ Dr. Raashid Hamid, MBBS, MS, Senior Resident, ${ }^{2}$ Dr. AH Shera, MBBS, MS, Mch. Head of Department of Paediatric Surgery, \\ ${ }^{3}$ Dr. NA Bhat, MBBS, MS, Mch, ${ }^{4}$ Dr. Aijaz A Baba, MBBS, MS, Mch, ${ }^{5}$ Dr. Abdul Rashid, MBBS, MS, Mch. All from the Department \\ of Paediatric Surgery, Sherikashmir Institute of Medical Sciences, Soura, Srinager, Jammu and Kashmir, India.
}

Address for correspondence: Dr. Raashid Hamid, E-mail: drraashidhamid@gmail.com

\begin{abstract}
Colonic atresia and stenosis are rare causes of intestinal obstruction in the infant. Only 10 cases have been reported in Literature since 1966 and only one late-onset case has been reported in Literature until now. We describe the case of a 3 day old baby presenting with abdominal distension, failure to pass meconium and vomiting. X-ray of the abdomen showed dilated gut loops. Exploratory laparotomy was performed. At the junction of descending and sigmoid colon a stenosis was found, laparotomy also revealed a perforation of transverse colon. Transverse colostomy and a mucous fistula of sigmoid colon was performed after resecting stenosing segment and colon distal to perforation site upto stenosing site. Diagnosis was confirmed on histopathology. Colostomy was close after six weaks with uneventful recovery. Considering both the Literature and our case, congenital colonic stenosis should be considered one of the rare differential diagnoses in a neonate presenting as complete or partial intestinal obstruction.
\end{abstract}

Key words: Colonic Stenosis, Perforation, Obstruction

\section{Introduction}

Colonic stenosis is a rare clinical entity. Incidence reported is $1 / 40,000$ births. Only 10 cases have been reported in the literature since $1966^{1}$. Colonic stenoses are associated with colonic atresias and both problems contribute about $1.8-15 \%$ of intestinal atresias'. AbuJedeh reports a case and refers to a total nine cases reported since $1941^{2}$. The ascending and transverse colon tend to be more affected. The length of segment can range from $3-15 \mathrm{~cm}^{2}$.

Clinical manifestations may present from birth to childhood period and include constipation, abdominal bloating and vomiting. It may also present as inability to pass meconium. Ours is the first case of congenital colonic stenosis (CCS) involving descending colon and leading to perforation in the transverse colon in a three day old neonate.

\section{The Case}

We presented a case of a neonate three days old having abdominal distention and inability to pass meconium and vomiting since birth. X-ray abdomen of the neonate revealed dilated colon, small gut and few air fluid levels (Figure 1). On digital rectal examination, anus was normal and rectum was empty. Rest of the examination including chest, CVS, musculoskeletal system, CNS was normal. On $3^{\text {rd }}$ day of birth, the abdominal distention increase in severity and exploratory laparotomy was planned. Intraoperative findings revealed a perforation in transverse colon wrapped by the omentum and a stenosed area of about $1 \mathrm{~cm}$ just at the junction of descending and sigmoid colon. Saline was injected into the colon which could not pass beyond the stenosed segment (Figure 2,3,4). This confirmed the complete obstruction of the colon. Rest of the gut and stomach were normal. The perforation site was brought as end colostomy the colon distal to perforation and up to stenosed segment was resected and sigmoid colon brought as mucous fistula (Figure 5). The biopsy of the stenotic segment demonstrated complete stenosis of the colon.

Neonate postoperatively progressed well and was discharged on $6^{\text {th }}$ postoperative day. Colostomy was closed after 8 weeks of surgery and baby is doing well till date. 


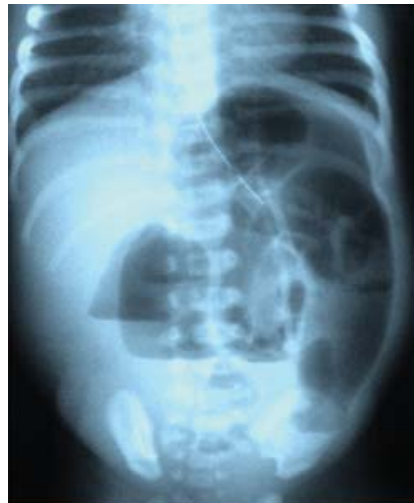

Fig 1: Plain X-Ray abdomen showing dilated gut loops and air fluid levels

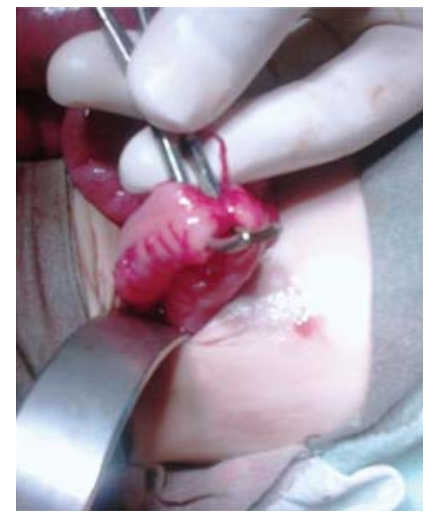

Fig 2: Per operative findings during laprotomy showing stenosis of colon.

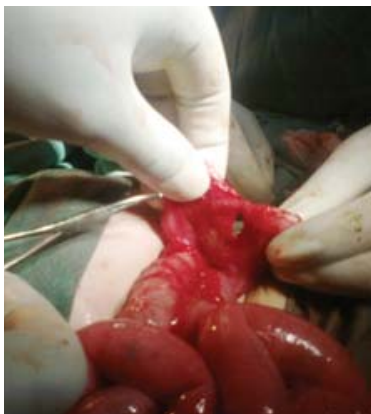

Fig 3: Per operative finding showing stenosing segment of colon (side view)

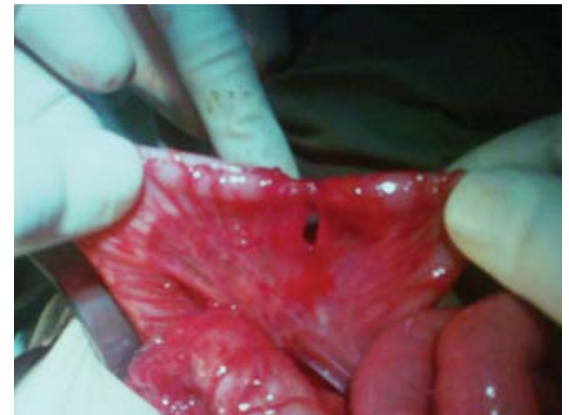

Fig 4: Per operative findings showing stenosed segment of colon (magnified view)

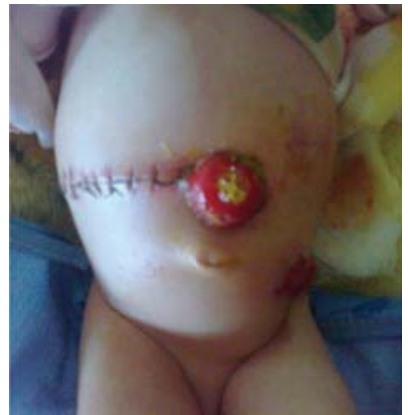

Fig 5: Post operative photograph showing end colostomy with a mucous fistula

\section{Discussion}

Colonic atresias and stenosis may contribute about $2-15 \%$ of all gut atresias. Isolated colonic stenosis is even rarer than atresias ${ }^{1}$. Binniger had reported first case of colonic stenosis in 1673 and in 1922; Gaub described the first survival of patient with this anomaly after colostomy ${ }^{3}$. Louw described that type IV colonic atresia as colonic stenosis ${ }^{4}$. One case of sigmoid stenosis was described by Santulli and Blanc ${ }^{5}$. Pai and Pai reported a case of rectosigmoid stenosis in a 4 month old female infant ${ }^{6}$. Rectal stenosis was reported in a 3 day old full term infant ${ }^{7}$. As described these lesions are uncommon but may present in any age group. Prompt surgical intervention is needed for primary anastomosis ostomy formation fallowed by closure was recommended depending upon the condition of patient.

The possible etiology of congenital colonic stenosis include in vitro vascular insult which may occur due to embolus in mesenteric circulation, fetal herniation, kinks, intussuception of gut ${ }^{5,8,9}$. Maternal use of cocaine may also be implicated in neonatal intestinal ischaemia ${ }^{10}$.

Clinical features include vomiting, abdominal distention and inability to pass meconium or passage of only small amount of meconium but some patients may remain asymptomatic for varying periods of time depending upon the severity of the stenosis. It may present in early neonatal period as in our case. The condition has to be differentiated in neonates from atresias, malrotation and neonatal Hirschprung's disease, older children may present as loss of weight, failure to gain weight and failure thrive

Typical X-ray findings include dilated proximal gut loops and air fluid levels. Barium enema preoperatively may be normal or in some cases depict failure of dye to progress in proximal colonic segment. Colonscopy may sometime help in diagnosis but confirmation of the colonic stenosis is only after the exploration of abdomen, resection of diseased segment histopathology ${ }^{11}$.

\section{Conclusion}

Our case being first of its instance is a first report of congenital stenosis of descending colon with proximal clonic perforation in early neonatal period. Diagnosis was not made until exploratory laparotomy was performed. Considering both review of literature and our present case, it is wise to keep in mind congenital colonic stenosis as a differential diagnosis in a neonate presenting as complete or partial intestinal obstruction. 


\section{References}

1. Ruggeri G, Libri M, Gargano T, Pavia S, Pasini L, Tani G, Lima M. Congenital colonic stenosis: a case of late onset. Pediatr Med Chir 2009; May-Jun;31(3):130-3

2. Alfonso Galvan Montano, Maria de Lourdes Suarez Roa and Erika Carmano Moreno Subdireccion de Pediatria Division de Investigacion Clin Cirugia General Cir Cir 2010;78:259-61.

3. Peck DA, Lynn HB, Harris LE: Congenital atresia and stenosis of the colon. Arch Surg 1963;87:428-39.

4. Louw JH: Congenital intestinal atresia and stenosis in the newborn: observation on its pathogenesis and treatment. Ann R Coll Surg Engl 1959;25:209-34.

5. Santulli TV, Blanc WA: Congenital atresia of the intestine: pathogenesis and treatment. Ann Surg 1961;154:939-48.

6. Pai GK, Pai PK: A case of congenital colonic stenosis presenting as rectal prolapse. J Pediatr Surg 1990;25:699-700.

7. Richdorf LF: Involvement of the colon in the newborn infant. Lancet 1944;64:156.
8. Powell RW, Raffensperger JG: Congenital colonic atresia. J Pediatr Surg 1982;17:163-64.

9. Philippart Al:Atresia, stenosis and other obstructions of the colon. Pediatric Surgery. Welch KJ, Randolph JG, Ravitch MM, et al (eds). Chicago, Year Book, Vol 2, 1986, p 984.

10. Hall TR, Zaninovic A, Barrett C, et al: Neonatal intestinal ischemia with bowel perforation: an in utero complication of maternal cocaine abuse. Am J Roentgenol 1992;158:1303-304.

11. Franken EA. Gastrointestinal Imaging in Pediatrics. 2nd ed. New York:Harper \& Row;1982, pp 286-87.

12. Sax EJ: Pediatric case of the day. Congenital colonic stenosis. Am J Roentgenol 1991;156:1315-17.

13. Benson CD, Lofti MW, Brough AJ: Congenital atresia and stenosis of the colon. J Pediatr Surg 1968;3:25357.

14. Ladd WE, Gross RE: Congenital stenosis of the intestine and colon. Abdominal Surgery of Infancy and Childhood. Philadelphia, WB Saunders Co, 1941, pp 44-52.

\section{How to cite this article ?}

Hamid R, Shera AH, Bhat NA, Baba A, Rashid A. Congenital Descending Colonic Stenosis with Perforation of Transverse Colon in a Neonate: A Case Report. J Nepal Paediatr Soc 2012;32(1):73-75. 